\title{
GERMINAÇÃO E ARMAZENAMENTO DE SEMENTES DE Virola surinamensis (Rol.) Warb. (MYRISTICACEAE) ${ }^{1}$
}

\author{
Juliana Domingues Limas², Breno Marques da Silva e Silva ${ }^{3}$ e Wilson da Silva Moraes ${ }^{4}$
}

\begin{abstract}
RESUMO - Este trabalho teve como objetivo estudar a germinação e o armazenamento de sementes de Virola surinamensis (Rol.) Warb. em condições de laboratório, no Estado do Amapá, Brasil. Para tanto, frutos foram coletados na Reserva Particular de Patrimônio Natural, "Ekinox", localizada em Macapá. Sementes recémcolhidas do lote original apresentaram teor médio de água de $24 \%$ e baixo ganho de água durante a embebição. Devido às diferenças no tamanho e, ou, peso, as sementes colhidas foram divididas em dois grupos: grandes e pequenas. Independentemente do tamanho da semente, a maior porcentagem de germinação e o menor tempo médio de germinação ocorreram a $30^{\circ} \mathrm{C}$. Sementes armazenadas por 30 dias em condição ambiente $\left(27^{\circ} \mathrm{C}\right.$ \pm 3 e $75 \% \pm 5 \mathrm{UR})$ e em germinador $\left(20^{\circ} \mathrm{C}\right.$ e $58 \%$ UR) apresentaram viabilidade abaixo de $2 \%$, ressaltandose o comportamento recalcitrante de sementes de Virola surinamensis.
\end{abstract}

Palavras-chave: Ucuúba, virola, tamanho da semente, temperatura e recalcitrância.

\section{GERMINATION AND STORAGE OF SEEDS OF Virola surinamensis (Rol.) Warb. (MYRISTICACEAE)}

\begin{abstract}
The objective of this work was to study the germination and the storage of seeds of Virola surinamensis (Rol.) Warb. in laboratory conditions, in the State of Amapa, Brazil. Fruits were harvested in the "Ekinox" Private Reserve of Natural Patrimony, located at Macapa. Seeds recently harvested in the original seedlot showed $24 \%$ mean water content and lower water gain, during soaking. Due to differences in the size and/ or weight, the seeds were separated in two groups: large and small. Independently of seed size, the highest germination percentage and the lower average germination time occurred at $30^{\circ} \mathrm{C}$. Seeds stored under natural $\left(27^{\circ} \mathrm{C} \pm 3\right.$ e $\left.75 \% \pm 5 \mathrm{RU}\right)$ or germination chamber conditions $\left(20^{\circ} \mathrm{C}\right.$ e $\left.58 \% \mathrm{RU}\right)$ showed viability lower than $2 \%$, attesting the recalcitrant behavior of Virola surinamensis.
\end{abstract}

Keywords: Ucuúba, virola, seed size, temperature and recalcitrance.

\section{INTRODUÇÃO}

A exploração desordenada das florestas da Amazônia, com conseqüente diminuição da biodiversidade e perda de recursos genéticos de espécies com elevados valores econômicos, acarreta problemas ambientais, como a redução da cobertura florestal, a destruição dos mananciais hídricos e o prejuízo à fauna e flora, especialmente às espécies em risco de extinção (COUTO et al., 2004).

Virola surinamensis (Rol.) Warb. (Myristicaeae), conhecida como virola ou ucuúba, é uma espécie considerada tipicamente amazônica, cujo "habitat" são a várzea e os igapós (LEITE e LLERAS, 1993). No Brasil, concentra-se na Bacia Amazônica, atingindo todo o Estado do Amazonas, Pará, parte do Maranhão, Ceará e Goiás, onde predomina em locais alagados, nas margens

\footnotetext{
${ }^{1}$ Recebido em 15.02.2006 e aceito para publicação em 20.10.2006.

${ }^{2}$ Campus Experimental de Registro/UNESP, Rua Tamekishi Takano, 5, Centro, 11900-000 Registro-SP.E-mail:<judlima@ registro.unesp.br>.

${ }^{3}$ Programa de Pós-Graduação em Agronomia da FCAV/UNESP, Campus de Jaboticabal, Via de Acesso Prof. Dr. Paulo Donato Castellane, s/n. Jaboticabal-SP.

${ }^{4}$ Pólo Regional do Vale do Ribeira, APTA, Av. Wild José de Souza, 454, Centro, 11.900-000 Registro-SP.
} 
dos rios, igarapés, furos e paranás, e em áreas que possam ser atingidas pelas cheias (MAINIERI e CHIMELO, 1989). Apresenta grande potencial econômico, sendo sua madeira utilizada na fabricação de laminados (PAULINO FILHO, 1985) e de compensados (LORENZI, 2002).

Em face ao seu grande valor econômico, vem sendo intensamente explorada nos últimos anos, culminando com a extinção de algumas populações, resultante do extrativismo seletivo. Como conseqüência, apesar de ser considerada espécie florestal capaz de resistir à pressão de exploração pela atividade madeireira (MARTINI et al., 1998), foi incluída entre as espécies prioritárias para programas de conservação de recursos genéticos de grande valor econômico (IBAMA, 1992) e no Sistema de Controle de Madeira Serrada Contingenciada (BRASIL, 1999). Atualmente, é uma das espécies madeireiras mais exportadas pela indústria madeireira do estuário amazônico (LEITE, 2006).

Diante desse quadro, surge a necessidade de determinar estratégias de regeneração que envolvam a germinação de sementes e o estabelecimento de plântulas, pois estes são eventos críticos na história de vida de uma espécie florestal (AGUIAR et al., 1993), bem como a preservação do potencial fisiológico das sementes durante o armazenamento.Assim, o objetivo deste trabalho foi estudar a germinação e o armazenamento de sementes de Virola surinamensis (Rol.) Warb.

\section{MATERIAL E MÉTODOS}

Sementes de Virola surinamensis foram coletadas de árvores-matriz, selecionadas de acordo com recomendações de Aguiar et al. (1993), na Reserva Particular do Patrimônio Natural "Ekinox", localizada em Macapá, Estado do Amapá, Brasil.

Os experimentos foram realizados no Laboratório de Sementes do Instituto de Pesquisas Científicas e Tecnológicas do Estado do Amapá (IEPA). O beneficiamento das sementes consistiu na remoção manual do pericarpo, conforme recomendado por Cunha et al. (1994) para sementes da mesma espécie.

Antes de iniciar os testes germinativos, foi determinado o peso médio de 100 sementes, bem como, o teor de água por meio da secagem em estufa a $105^{\circ} \mathrm{C} \pm 3$ durante $24 \mathrm{~h}$, de acordo com Brasil (1992), em quatro repetições de 10 sementes.

Na seqüência, devido às diferenças no tamanho, as sementes foram divididas em dois grupos, de acordo com a massa fresca: sementes menores que $1 \mathrm{~g}$ (pequenas) e maiores que $1 \mathrm{~g}$ (grandes).

Para os dois grupos de sementes (pequenas e grandes), foram feitas a pesagem inicial de quatro repetições de 50 sementes. Em seguida, as sementes foram colocadas para embeber em água destilada à temperatura ambiente, sendo pesadas após $0 ; 0,5 ; 1$; $2 ; 3 ; 4 ; 5 ; 6 ; 7 ; 8 ; 9 ; 10 ; 11 ; 12 ; 24 ; 48 ;$ e 72 h de embebição. Antes de cada pesagem, as sementes foram secadas em papel-toalha e posteriormente, recolocadas em água destilada. A partir dos valores das porcentagens consecutivas, calculou-se a porcentagem de ganho de água em relação ao peso inicial das sementes, a fim de estabelecer as curvas de embebição após análise de regressão polinomial.

Para determinar a influência do tamanho da semente e da temperatura na germinação, foi montado um experimento em delineamento inteiramente casualizado, em esquema de fatorial $2 \times 3$, sendo dois tamanhos de sementes e três temperaturas, em quatro repetições de 30 sementes. Para tal, as sementes foram colocadas em caixas plásticas contendo vermiculita $(60 \% \pm 5 \%$ da capacidade de retenção de água) e mantidas em germinadores com fotoperíodo de $12 \mathrm{~h}$, nas temperaturas constantes de 25,30 e $35^{\circ} \mathrm{C}$.

A germinação das sementes foi avaliada diariamente, adotando-se a emergência da radícula como critério de germinação (BEWLEY e BLACK, 1994). A partir de contagens diárias de sementes germinadas foram determinados a porcentagem de germinação e o tempo médio de germinação, conforme proposto por Labouriau (1983). Os dados de porcentagem de germinação foram transformados em [arco sen $(\%)^{0,5}$ ], para a normalização de sua distribuição. No entanto, nas tabelas são apresentadas as médias originais. Para comparação das médias, utilizou-se o teste de Tukey a 5\% de probabilidade.

Na seqüência, as sementes dos dois grupos de tamanhos foram armazenadas em bandejas plásticas descobertas sob condição ambiente $\left(27^{\circ} \mathrm{C} \pm 3\right.$ e $75 \%$ \pm 5 de umidade relativa do ar - UR) e em germinador $\left(20^{\circ} \mathrm{C} \pm 1\right.$ e $58 \% \pm 2$ de UR). Mensalmente, foram realizados testes germinativos, sendo as sementes colocadas para germinar em caixas plásticas contendo vermiculita $(60 \%$ \pm 5 da capacidade de retenção de água), mantidas em germinadores com fotoperíodo de $12 \mathrm{~h}$, à temperatura constante de $30^{\circ} \mathrm{C}$. O delineamento experimental adotado 
foi o inteiramente casualizado, com quatro repetições de 30 sementes.

\section{RESULTADOS E DISCUSSÃO}

Testes iniciais realizados após a coleta das sementes de Virola surinamensis demonstraram que o peso médio de 100 sementes foi de 99,9 g, o diâmetro médio da semente $13,9 \mathrm{~mm}$ e teor médio de água $24 \%$.

O peso das sementes classificadas como pequenas variou entre 0,63 e 0,95 g, com peso médio de $0,75 \mathrm{~g}$, e o peso das sementes classificadas como grandes, entre 1,00 e 1,91 g, com peso médio de 1,28 g. Segundo Marcos-Filho (2005), a variação do tamanho das sementes dentro de uma mesma espécie e, ou, cultivar está relacionada, principalmente, com as condições ambientais às qual foi submetida à planta-mãe durante a maturação das sementes, bem como as suas características morfológicas.

Segundo Bewley e Black (1994), a maioria das sementes apresenta de 5 a $20 \%$ de água, com base em sua massa fresca. Nessas, a embebição se inicia com o rápido ganho de água, seguido pela estabilização e pelos principais eventos metabólicos, e, posteriormente, a semente volta a ganhar água como conseqüência da germinação.

A porcentagem de ganho de água em Virola surinamensis foi muito baixa durante a embebição nas sementes dos dois grupos de tamanhos, sendo inferior a 5\%, ao final de 72 h de embebição (Figura 1). Provavelmente, o reduzido ganho de água pela semente durante a embebição tenha sido consequiência do alto teor de água nela contida.

Em sementes ortodoxas, o ganho de água atinge valores mais altos, de 40 a $100 \%$ em relação ao peso inicial (GARCIA e DINIZ, 2003; CABRAL et al., 2003), e em sementes recalcitrantes o baixo ganho de água se deve ao fato de estas continuarem hidratadas até o final do desenvolvimento e maturação, apresentando a capacidade de germinar imediatamente após a separação da planta-mãe, em razão de seu elevado teor de água (FINCH-SAVAGE et al., 1992), sem a necessidade de hidratação adicional exógena (FARRANT et al., 1992).

Com relação à influência do tamanho da semente e da temperatura na porcentagem de germinação, não houve interação significativa entre esses dois fatores. Independentemente do tamanho da semente, a maior porcentagem de germinação ocorreu a $30^{\circ} \mathrm{C}(76,0 \%)$, não havendo diferença na porcentagem de germinação das sementes a 25 e $35^{\circ} \mathrm{C}$ (Tabela 1). Contudo, Cunha et al. (1992) obtiveram apenas 23,2\% de germinação em sementes da mesma espécie, com teor médio de água de $25,4 \%$, na mesma temperatura. Essa diferença na porcentagem de germinação pode ser atribuída, em parte, à diferença no teor de água da semente. Sementes pequenas apresentaram porcentagem de germinação média de $48,5 \%$ e as sementes grandes de $57,2 \%$, diferindo entre si, independentemente da temperatura (Tabela 1). Esse resultado indica a relação entre tamanho da semente e sua qualidade fisiológica.

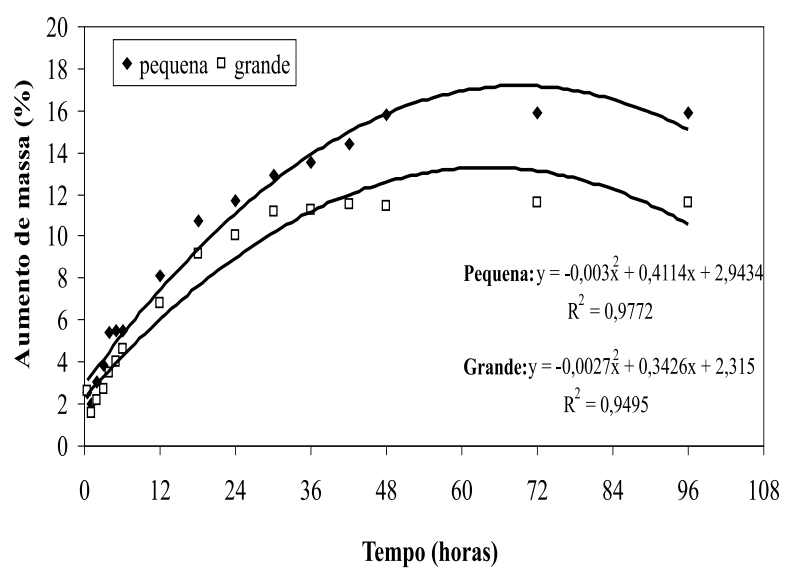

Figura 1 - Aumento de massa em relação à massa fresca inicial obtido durante a embebição em água destilada de sementes de Virola surinamensis.

Figure 1 - Increasing of mass in relation to initial fresh mass during soaking in distilled water Virola surinamensis seeds.

Tabela 1 - Efeito da temperatura e do tamanho da semente na porcentagem de germinação de sementes de Virola surinamensis

Table 1 - Effect of temperature and seed size on the germination percentage of Virola surinamensis

\begin{tabular}{|c|c|c|c|}
\hline \multirow[t]{2}{*}{ Temperatura $\left({ }^{\circ} \mathrm{C}\right)$} & \multicolumn{2}{|c|}{ Tamanho } & \multirow[b]{2}{*}{ Médias } \\
\hline & Pequena & Grande & \\
\hline 25 & 40,00 a $\mathrm{A}$ & 50,00 a $\mathrm{A}$ & $45,00 \mathrm{~B}$ \\
\hline 30 & 77,01 a $\mathrm{A}$ & 75,00 a $\mathrm{A}$ & $76,00 \mathrm{~A}$ \\
\hline 35 & 28,34 a $\mathrm{A}$ & 46,68 a $A$ & $37,51 \mathrm{~B}$ \\
\hline Médias & $48,45 \mathrm{~b}$ & 57,23 a & \\
\hline
\end{tabular}

Médias seguidas da mesma letra maiúscula na coluna e minúscula na linha não diferem entre si, a $5 \%$ de probabilidade, pelo teste de Tukey.

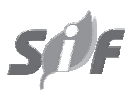

R. Árvore, Viçosa-MG, v.31, n.1, p.37-42, 2007 
Não há uma clara relação entre tamanho de sementes e porcentagem final de germinação. Em pupunheira (Bactris gasipaes), quanto maior o tamanho das sementes, maior a porcentagem de germinação (LEDO et al., 2002). Ao contrário, a germinação de sementes de Virola koschnyi, Eucalyptus grandis e E. urophylla, Acacia senegal, Dimocarpus longan e Mimosa caesalpiniifolia não foram afetadas pelo tamanho da semente (AGUIAR et al., 1979; FERREIRAeTORRES, 2000;ALVESetal., 2005; OLIVEIRA et al., 2005). Em Virola koschnyi, o tamanho da semente não afetou a germinação, porém houve relação entre o tamanho da semente e o vigor da plântula, sendo que sementes de maior tamanho produziram plântulas mais vigorosas (GONZALEZ, 1993).

A temperatura de germinação e o tamanho da semente influenciou conjuntamente o tempo médio de germinação (Tabela 2). A $25^{\circ} \mathrm{C}$, sementes grandes germinaram mais lentamente (27,2 dias) quando comparadas com as pequenas ( 17,1 dias). Ao contrário, a $35^{\circ} \mathrm{C}$ sementes pequenas germinaram mais lentamente $(29,7$ dias $)$ em relação às grandes (26,3 dias). No entanto, a $30^{\circ} \mathrm{C}$ não houve diferenças no tempo médio de germinação para os dois tamanhos de sementes. Assim, independentemente da temperatura, sementes pequenas apresentaram menor tempo médio de germinação quando comparadas com sementes grandes.

Também, para a velocidade de germinação não houve padrão definido entre tamanho e vigor. Há relatos comprovando que sementes médias e grandes de pupunha, E. grandis e E. urophylla germinaram mais rapidamente que as pequenas (AGUIAR et al., 1979; LEDO et al., 2002). Noutras espécies, como Acacia senegal e Dimocarpus longan, o tamanho das sementes não afetou a velocidade de germinação(FERREIRA e TORRES, 2000; OLIVEIRA et al., 2005).

Tabela 2 - Efeito da temperatura e do tamanho das sementes no tempo médio de germinação de sementes de Virola surinamensis

Table 2 - Effect of temperature and seed size on the germination mean time of Virola surinamensis seeds

\begin{tabular}{cccc}
\hline Temperatura $\left({ }^{\circ} \mathrm{C}\right)$ & \multicolumn{2}{c}{ Tamanho } & \\
\cline { 2 - 3 } & Pequena & Grande & Médias \\
\hline 25 & $17,14 \mathrm{~b} \mathrm{~B}$ & 27,24 a A & $22,19 \mathrm{~B}$ \\
30 & 17,25 a B & 17,15 a B & $17,20 \mathrm{~B}$ \\
35 & 29,67 a A & $26,34 \mathrm{~b} \mathrm{~A}$ & $28,00 \mathrm{~A}$ \\
\hline Médias & 21,35 a & $23,57 \mathrm{~b}$ & \\
\hline
\end{tabular}

Médias seguidas da mesma letra maiúscula na coluna e minúscula na linha não diferem entre si, a 5\% de probabilidade, pelo teste de Tukey.

R. Árvore, Viçosa-MG, v.31, n.1, p.37-42, 2007
A temperatura ótima de germinação para sementes de várias espécies florestais tropicais varia de 20 a 35 ${ }^{\circ} \mathrm{C}$ (AGUIAR et al., 1993), faixa que abrange a temperatura indicada como mais adequada para a germinação da espécie em estudo.

De modo geral, independentemente do tamanho das sementes, as maiores porcentagens e menores tempos médios de germinação ocorreram quando da germinação sob temperatura constante de $30^{\circ} \mathrm{C}$. Diversas espécies nativas da floresta amazônica, como Maquira sclerophylla (MIRANDA e FERRAZ, 1999), Cariniana micrantra (IMAKAWA eFERRAZ, 1995), Ceibapentandra (VARELA et al., 1999) e Clarisia racemosa (FERRAZ e VARELA, 2003) também apresentaram germinação ótima a $30^{\circ} \mathrm{C}$.

Sementes de Virola surinamensis armazenadas por 30 dias em condição ambiente $\left(27^{\circ} \mathrm{C} \pm 3\right.$ e $75 \% \pm 5$ de umidade relativa do ar) e em germinador $\left(20^{\circ} \mathrm{C} \pm 1\right.$ e $58 \%$ \pm 2 UR) apresentaram porcentagem de germinação média de 0,83 e $1,67 \%$ e teor médio de água de 4,5 e 4,9\%, respectivamente, independentemente do tamanho da semente. Esses resultados corroboram os obtidos por Rodrigues (1980), trabalhando com a mesma espécie, que observaram viabilidade das sementes após a secagem natural por apenas 20 dias após a colheita, ressaltandose a dificuldade em manter a longevidade, tanto sob condições naturais quando utilizando técnicas convencionais de armazenamento.

Considerando que o teor médio de água em sementes recém-coletadas foi de $24 \%$, verificou-se que houve redução acentuada no conteúdo de água da semente ao longo do período de armazenamento, nas duas condições de armazenamento estabelecidas.

Cunha et al. (1992) classificaram sementes de Virola surinamensis como recalcitrantes. Esse tipo de semente depende de alto teor de umidade para manter sua viabilidade e possui embrião com período de vida curto (RODRIGUES, 1980), o que concorda com o fato de essa espécie ser típica de floresta de várzea, cuja viabilidade da semente pode ser prolongada quando mantida em água. Sementes recalcitrantes são comuns em florestas tropicais, onde o ambiente favorece a germinação e o estabelecimento da plântula (PAMMENTER e BERJAK, 2000). Apresentam também como característica baixa absorção de água durante a embebição, diferentemente do que ocorre na maioria das sementes consideradas ortodoxas (BEWLEY eBLACK, 1994), resultado também observado neste estudo (Figura 1). 
Segundo Farrant et al. (1988), nesse tipo de sementes a água subcelular está fortemente associada às superfícies macromoleculares, assegurando a estabilidade de membranas e macromoléculas. A perda de água estrutural, durante o processo de secagem acarreta alteração de sistemas metabólicos e de membranas, iniciando, dessa forma, os processos de deterioração (BOVI et al., 2004).

Os resultados apresentados indicaram a temperatura de $30{ }^{\circ} \mathrm{C}$ como a mais adequada para germinação e confirmaram novamente o comportamento recalcitrante das sementes de Virola surinamensis, tornando evidente a necessidade de mais estudos envolvendo, sobretudo, o armazenamento de sementes, uma vez que as condições testadas não foram apropriadas para manutenção de sementes com elevado potencial fisiológico.

\section{CONCLUSÕES}

Pelos resultados, pode-se concluir que:

- A temperatura mais adequada para a germinação de sementes é $30^{\circ} \mathrm{C}$.

- O armazenamento de sementes em bandejas na temperatura ambiente $\left(27^{\circ} \mathrm{C} \pm 3\right.$ e $75 \% \pm 5 \%$ de umidade relativa do ar - UR) e em germinador $\left(20^{\circ} \mathrm{C} \pm 1\right.$ e $58 \%$ \pm 2 ) é inviável, pois a semente exibe comportamento recalcitrante.

\section{REFERÊNCIAS}

AGUIAR, I.B. et al. Influência do tamanho sobre a germinação e o vigor de sementes de eucalipto.

Revista Brasileira de Sementes, v.1, n.1, p.53-58, 1979.

AGUIAR, I.B.; PIÑA-RODRIGUES, F.C.M.; FIGLIOLIA, M.B. Sementes florestais tropicais. Brasília: ABRATES, 1993. 350p.

ALVES, E.U. et al. Influência do tamanho e da procedência de sementes de Mimosa caesalpinifolia Benth. sobre a germinação e vigor. Revista Árvore, v.29, n.6, p.877-885, 2005.

BEWLEY, J. D.; BLACK, M. Seeds: Physiology of development and germination. New York: Plenum Press, 1994. 445p.

BOVI, M.L.A.; MARTINS, C.C.; SPIERING, S.H. Desidratação de sementes de quatro lotes de pupunheira: efeitos sobre a germinação e o vigor. Horticultura Brasileira, v.22, n.1, p.109-112, 2004.
BRASIL. Ministério da Agricultura e Reforma Agrária. Regras para análise de sementes. Brasília-DF: LAVARV/ SNAD, 1992. 365p.

BRASIL. Ministério do Meio Ambiente. Instrução normativa $n^{\circ} \mathbf{1}-08$ de janeiro de 1999. Brasília: 1999. 1 p.

CABRAL, E.L.; BARBOSA, D.C. A.; SIMABUKURO, E.A. Armazenamento e germinação de sementes de Tabebuia aurea (manso) Benth. e Hook. f. ex. S. Moore. Acta Botanica Brasilica, v. 17, n.4, p.609-617, 2003.

COUTO, J.M.F. et al. Desinfestação e germinação in vitro de sementes de mogno (Swietenia macrophylla King). Revista Árvore, v.28, n.5, p.633-642, 2004.

CUNHA, R.; PEREIRA, T.S.; CARDOSO, M.A. Efeito do dessecamento sobre a viabilidade de sementes de Virola surinamensis (Rol.) Warb. Revista Brasileira de Sementes, v.14, n.1, p.69-72, 1992.

CUNHA, R.; PEREIRA, T.S.; CARDOSO, M.A. Dados preliminares sobre a germinação de sementes de ucuúba. Colombo: Embrapa-CNPF, 1994. 2p. (Comunicado Técnico, 1).

FARRANT, J.M.; PAMMENTER, N.W.; BERJAK, P. Recalcitrance - a current assessment. Seed Science Technology, v.16, n.1, p.155-166, 1988.

FARRANT, J.M.; PAMMENTER, N.W.; BERJAK, $\mathrm{P}$. Development of the recalcitrant (homoiohydrous) seeds of Avicennia marina: anatomical, ultrastructural and biochemical events associated with development from histodifferentiation to maturation. Annals of Botany, n.70, p.75-86, 1992.

FERRAZ, I.D.K.; VARELA, V.P. Temperaturas cardeais de germinação e sensibilidade ao resfriamento das sementes de guariúba (Clarisia racemosa Ruiz et Pavon. - Moraceae). Revista Brasileira de Ciências Agrárias, n.39, p.183-191, 2003.

R. Árvore, Viçosa-MG, v.31, n.1, p.37-42, 2007 
FERREIRA, M.G.R.; TORRES, S.B. Influência do tamanho das sementes na germinação e no vigor de plântulas de Acacia senegal (L.) Willd.

Revista Brasileira de Sementes, v.22, n.1, p.271-275, 2000.

FINCH-SAVAGE, W.E. et al. Seed development in the recalcitrant species Quercus robur L.: water status and endogenous absisic acid levels. Journal Experimental Botany, n.43, p.671-679, 1992.

GARCIA, Q.S.; DINIZ, I.S.S. Comportamento germinativo de três espécies de Vellozia da Serra do Cipó, MG. Acta Botanica Brasílica, v.17, n.4, p.487-494, 2003.

GONZALEZ, J.E. Effect of seed size on germination and seedling vigor of Virola koschnyi Warb. Forest Ecology and Management, v.57, n.1-4, p.275-28, 1993.

IB AMA. Portaria $n^{\circ} 37$ - 03 de abril de 1992. Brasília: 1992. 6p.

IMAKAWA, A.M.; FERRAZ, I.D.K. Germinação e características biométricas de Cariniana micrantha Ducke (Lecythidaceae) na Amazônia Central. Boletim do Museu Paraense Emílio Goeldi, Série Botânica, v.11, n.1, p.27-41, 1995.

LABOURIAU, L.G. A germinação de sementes. Washington: Secretaria da OEA, 1983. 179p.

LEDO, A.S. et al. Efeito do tamanho de semente, do substrato e pré-tratamento em sementes de pupunha. Ciência Agronômica, v.33, n.1, p.29-32, 2002.

LEITE, A.M.C.; LLERAS, E. Áreas prioritárias na Amazônia para a conservação dos recursos genéticos de espécies florestais nativas: fase preliminar. Acta Botânica Brasilica, v.7, n.1, p.61-94, 1993.

LEITE, H. G. et al. Função de afilamento para Virola surinamensis (ROLL.) WARB. Revista Árvore, v.30, n.1, p.99-106, 2006.
LORENZI, H. Árvores brasileiras: manual de identificação e cultivo de plantas arbóreas nativas do Brasil. 4. ed. Nova Odessa: Instituto Plantarum, 2002. 368p. v.1.

MARCOS-FILHO, J. Fisiologia de sementes: de plantas cultivadas. Piracicaba: FEALQ. 2005. 495p.

MAINIERI, C.; CHIMELO, J.P. Fichas de características das madeiras brasileiras. 2. ed. São Paulo: IPT, 1989. 418p. (Publicação IPT, 1791).

MARTINI, A.; ROSA, N.A.; UHL, C. Espécies de árvores potencialmente ameaçadas pela atividade madeireira na Amazônia. Belém: IMAZON, 1998. 35p.

MIRANDA, P.R.M.; FERRAZ, I.D.K. Efeito da temperatura na germinação de sementes e morfologia da plântula de Maquira sclerophylla (Ducke) C. C. Berg. Revista Brasileira de Botânica, v.22, n.2, p.303-307, 1999. Suplemento.

OLIVEIRA, I.V. et al. Influência do tamanho da semente na emergência das plântulas de longan (Dimocarpos longan Lour). Revista

Brasileira de Fruticultura, v.27, n.1, p.171-172, 2005.

PAMMENTER, N.; BERJAK, P. Aspects of recalcitrant seed physiology. Revista Brasileira de Fisiologia Vegetal, v.12, p.56-69, 2000. Edição Especial.

PAULINO FILHO, H.F. Ecologia química da Família Myristicaceae. 1985. 336f. Tese (Doutorado em Química). Universidade de São Paulo, São Paulo, 1985.

RODRIGUES, W.A. Revisão taxonômica das espécies de Virola Aublet. (Myristicaceae) do Brasil. Acta Amazonica, v.15, n.1, p.1-127, 1980.

VARELA, V.P.; FERRAZ, I.D.K.; CARNEIRO, N.B. Efeito da temperatura na germinação de sementes de sumaúma (Ceiba pentandra (L.) Gaertn.). Revista Brasileira de Sementes, v.21, n.2, p.170-174, 1999. 